\title{
Undergraduate Leadership Students' Self-Perceived Level of Moral Imagination: An Innovative Foundation for Morality-Based Leadership Curricula
}

\author{
Summer F. Odom \\ Assistant Professor \\ Department of Agricultural Leadership, Education, \& Communications \\ 2116 TAMU \\ Texas A\&M University \\ College Station, TX 77843-2116 \\ summerodom@tamu.edu \\ Anthony C. Andenoro \\ Assistant Professor of Leadership Education \\ Department of Agricultural Education \& Communication \\ 219 Rolfs Hall \\ University of Florida \\ Gainesville, FL 32611-0540 \\ andenoro@ufl.edu \\ M'Randa R. Sandlin \\ Assistant Researcher \\ College of Tropical Agriculture and Human Resources \\ 3050 Maile Way \\ University of Hawai'i at Mānoa \\ Honolulu, HI 96822-2231 \\ mranda.sandlin@yahoo.com \\ Jaron L. Jones \\ Doctoral Graduate Assistant \\ Department of Agricultural Education, \& Communications \\ 411 Rolfs Hall \\ University of Florida \\ Gainesville, FL 32611-0540 \\ jaronljones@ufl.edu
}

\begin{abstract}
Leadership educators are faced with the challenge of preparing students to serve organizations and people in dynamic and ever changing contexts. The purpose of this study was to examine undergraduate leadership students' self-perceived level of moral imagination to make recommendations for moral imagination curricula. Moral imagination is the foundation of moral decision-making, which is critical to develop for aspiring leaders. It also has the potential to
\end{abstract}


develop resilience and hardiness in organizations and people, which is paramount for community sustainability. Students in leadership courses at two universities were surveyed to measure their level of moral imagination in terms of three constructs: reproductive, productive, and creative imagination. One hundred fifty-one leadership students completed the instrument. It was found that participants had moderate moral imagination abilities with their highest scoring abilities in productive imagination. Recommendations lie in educational opportunities, curricula structure, and teaching techniques.

\section{Introduction}

Leadership educators are faced with the challenge of preparing students to serve organizations and people in dynamic and ever changing contexts. This challenge is complicated by a morally complex landscape (Macintyre, 2007), which provides a veritable minefield of potentially damaging options that can cut at the morally fragile credibility of organizations. With an increasingly multicultural workforce and the impacts of globalization, new values and beliefs have been introduced into organizations which require leaders to address problems in new, creative ways (Vidaver-Cohen, 1997). Further, individuals in positional authority often make decisions based on narrow mental models of how they view the world (Enlow \& Popa, 2008; Werhane, 1999). In concert, these factors create a perfect storm for poor and possibly immoral practice. However, the development of strategically placed curricula grounded in the idea of moral imagination may provide a welcomed advantage for students aspiring to serve in leadership positions upon graduation.

\section{Understanding the Components of Moral Imagination}

In its most basic principles, the incorporation of moral imagination into leadership curricula is not new. Leadership educators have been teaching moral development and imagining or visioning for many years and are educational outcomes in many leadership programs (Pijanowski, 2007; White, 2006). Only recently have the two terms been combined. According to Werhane (1999, p. 5), "moral imagination entails ability to understand that context or set of activities from a number of different perspectives, the actualizing of new possibilities that are not context-dependent, and the instigation of the process of evaluating those possibilities from a moral point of view." Moral imagination has been shown to improve moral decision-making (Werhane, 1998). To fully understand this idea it is critical to unpack the idea of moral imagination.

Moral leadership. Leaders face complex situations where they may not always know how to act morally. Because of the complexity and variety of the situations leaders face, there is not likely to be one theory, which defines how a leader should behave in every situation. Greenfield (2004) describes that "leadership is a socially constructed relationship" (p. 190) and that moral leadership must include relevant social, historical, and cultural considerations; therefore, moral leadership is historically ill-defined. Differing situations including changed experience, technological development, and new information may require new values for a leader to examine (Yurtsever, 2003). 
Morals have traditionally been taught in tandem with ethics in business courses (Smith and Carter, 2012). Although some business courses link ethical and moral conduct theories to corporate success and legal implications, others teach moral awareness, moral reasoning, and consequences (Oddo, 1997; Sims \& Sims, 2001). In leadership education, morals are linked to personality, behavior, and self-awareness (Narvaez \& Lapsley; Narvaez, Lapsley, Hagele, \& Lasky, 2006; Williams, 2012). Unfortunately, Smith and Carter (2012) found that morals, as related to leadership, do not have an extensive research backing due to the fact that teachers lack confidence in the content area. In a study by Jenkins (2012), it was concluded that visioning and projecting to the future (imagining) is a crucial component to leadership success as a teaching method and a step to personal growth and leadership development.

Imagining. "Imagination is the exercise of generating new and novel mental images" (Enlow \& Popa, 2008, p. 24). It allows one to categorize, sort, and frame experiences to predict plausible outcomes (2008). Wenger (1998) defines imagination as "a process of expanding our self by transcending out time and space and creating new images of the world and ourselves" (p.176). He further addresses the implications of imagination for leaders, stating, "It is through imagination that we see our own practices as continuing histories that reach far into the past, and it is through imagination that we conceive of new developments, explore alternatives, and envision possible futures" (1998, p. 178). Imagination aids in one's ability to envision and actualize novel possibilities through a fresh point of view or conceptual scheme. Though often regarded as fanciful, unreal or strictly aesthetic thinking, imagination is a powerful cognitive tool that emphasizes engaging alternative perspectives and creating new possibilities for action (Enlow \& Popa, 2008).

Werhane (2006) states, "Sometimes companies get into trouble not because they deliberately meant to do the wrong thing... but because they did not question what they were doing or challenge the mind sets and methodologies with which they thought through issues" (p. 404). This lack of imagination can beget narrow perceptions or rigid conceptual schemes and mental models (Enlow \& Popa, 2008). Creating moral judgments are not always clear; more often than not they are a result of a delicate balance of context, evaluations of the situation, and the presence or absence of imagination. Understanding this, the practice of creative moral imagination can be implemented to help leaders criticize their own and others' points of view and generate adequate alternatives (Werhane \& Moriarty, 2009). Imagination can be a difficult skill to teach, given its nature, and requires unique pedagogical approaches to help individuals identify existing mental models while also engaging new ways of knowing and seeing (Enlow \& Popa, 2008).

\section{Moral Imagination}

Moral imagination is the ability to challenge operative mental models in order to discover new ways of framing ethical problems and providing innovative solutions (Werhane, 1999). This developmental pursuit towards increased moral imagination in students sets the foundation for more intentional decision-making and more morally sound practice. It also has the potential to develop resilience and hardiness in local and global communities. Maddi's three constructs of hardiness, commitment, control, and challenge, set the foundation for resilient communities in the face of adversity (1999). Inherently, moral imagination serves as the underpinning for the 
development of hardiness as individuals make decisions that engage and involve others (commitment), develop an understanding for how he or she can influence external outcomes (control), and learn from his or her experience (challenge).

Moral imagination is the ability to comprehend and evaluate possibilities within a particular set of circumstances through questioning and expanding one's operative mental framework. To effectively manage moral decision-making requires one to perceive norms, social roles, and relationships intertwined in any situation (Werhane \& Moriarty, 2009). In leadership, moral imagination shifts leaders away from ingrained ways of thinking and emphasizes reframing existing situations, moving beyond constraining mental models, and formulating innovative responses. Simply put, imagination is the critical cognitive link connection between what is and what might be (Enlow \& Popa, 2008). Werhane (2002) states that moral imagination "helps one to disengage from a particular process, evaluate the mindsets which it incorporates, and think more creatively within the constraints of what is morally possible" (p. 34). The development of moral imagination requires a heightened awareness of contextual moral dilemmas.

Moral imagination requires the active engagement of additional perspectives toward these dilemmas to enable leaders to reframe them and discover morally justifiable solutions (Werhane \& Moriarty, 2009). In describing the concept of placing yourself in another's position, Smith (2002) states, "When I condole with you for the loss of your only son, in order to enter into your grief, I do not consider what I, a person of character and profession should suffer, if I had a son and if that son was unfortunately to die; but I consider what I should suffer if I was really you, and I not only change circumstances with you, but I change persons and characters" (p. 374). It is this projection of self into another's experience that defines moral imagination. Moral imagination can be distinguished by three main characteristics: one, beginning not with the use of generalizations but with the use of observing a particular situation; two, entailing the ability to disengage from one's primary framework or to extend or adapt that framework in a meaningful way; and three, dealing not merely with fantasies but with possibilities or ideals that are viable and actualizable. The last characteristic is primarily concerned with what one should do (Werhane \& Moriarty, 2009). To have the ability to exercise these characteristics requires the ability to engage in the use of moral imagination.

\section{Moral Imagination and Education}

With the aforementioned call for morality in leadership, the question then becomes how to prepare future leaders and active citizens to lead with good moral reasoning? In an attempt to find an answer, there has been a rise in a number of initiatives designed to cultivate moral and ethical development within college students (Liddell \& Cooper, 2012). Swaner (2004) states, "There is ample evidence that cognitive aspects of personal and social responsibility - namely moral reasoning - continue to develop during the college years. This evidence suggests that educating personal and social responsibility is needed within higher education" (p. 44). Colleges and universities can utilize moral imagination to help students identify ethical events, assess various viewpoints concerning these events, and practice reframing the events using moral imagination (Enlow \& Popa, 2008). 
Whitely (2002) states that "one of the fundamental obligations of the modern college and university is to influence intentionally the moral thinking and action of the next generation of society's leaders and citizens" (p. 5). However, with the outcome of legal cases over years that gave students more rights and freedoms amongst universities, higher education put less emphasis on moral and religious values. The importance of these values has since been renewed due to recent events and public debate. Scandals within the corporate and political realm have created a distrust and lack of credibility in our leaders. The public is now demanding that there be an increase in leadership transparency and faith that organizations are operating with moral and ethical choices. Enlow and Popa (2008) state, "Poor leadership may in part be described as a lack of imagination - holding too firmly to the world as it is without exploring the world as it might be" (p. 25). Leaders may find themselves viewing situations through narrow perceptions or unbending conceptual schemes and mental models (2008). "Imagination in a leadership context is a cognitive orientation to the world that emphasizes engaging alternative perspectives and creating new possibilities for action" (2008, p. 24). It is the use of moral imagination which allows leaders to step outside of preconceived or ingrained mental models to develop the novel and innovative (2008).

Although it is plausible that the development of moral imagination could have significant impacts on students, organizational leadership, and community resilience, it is difficult to understand where to begin the curricular design process. This study informs that perspective. Data collected through this study will provide a baseline of leadership students' perceived level of moral imagination and will enable leadership educators to better understand the moral development level of undergraduate leadership students at land-grant universities to create more applicable and developmental leadership ethics and morality-based curricula.

\section{Conceptual Framework}

Yurtsever (2006) developed constructs for measuring moral imagination in terms of component dimensions. Based on the work of Werhane (1998), Yurtsever's (2006) instrument conceptualizes moral imagination as a three-stage process in how moral decisions are approached. The three stages are reproductive, productive, and creative imagination (Figure 1). As an individual moves though the stages, their competencies in moral imagination mature.

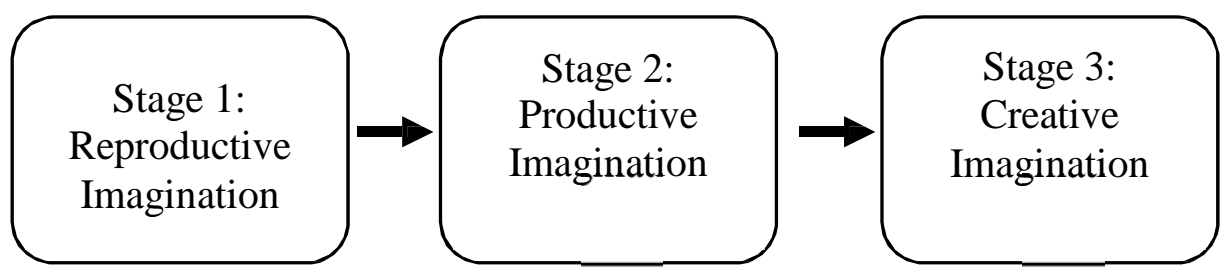

Figure 1. Progression of moral imagination development. Progression through the stages indicates a maturation in moral imagination competencies. Adapted from "Moral Imagination and the Search for Ethical Decision Making in Management" by P. H. Werhane, 1998, The Ruffin Series of the Society for Business Ethics, 1, pp. 75-98. 
In the first stage, reproductive imagination, individuals attain awareness of the contextual factors affecting moral perception. This includes awareness of one's context, the schema at play in the context, and what moral conflicts or dilemmas may arise as the schema progresses in the context. (Werhane, 1998). Vidaver-Cohen (1997) asserts that individuals must have an awareness of factors that affect the perception of a problem and how moral conflicts might arise before moving to the other stages. Factors that may affect the perception of the problem and how moral conflicts might arise include social, economic, organizational, and personal factors.

The productive imagination stage involves a reframing of the problem from various perspectives. In this stage, an individual would take new possibilities into account within the scope of their context (Werhane, 1998). Werhane (1998) defined productive imagination in the following way: "Revamping one's schema to take into account new possibilities within the scope of one's situation and/or within one's role" (p. 22).

Creative imagination is the third stage and consists of developing alternatives to solving problems, which are novel and morally acceptable. This stage involves the ability to imagine possibilities outside of the context, the ability to imagine reasonable possibilities based on the context and outside factors, and the ability to evaluate a the morality of these new possibilities, the status quo, and the potential outcomes if the new possibilities were implemented (Werhane, 1998).

\section{Purpose and Objectives}

The purpose of this study is to examine undergraduate leadership students' self-perceived level of moral imagination through: (a) an examination of the self-perceptions of undergraduate leadership students' level of moral imagination and (b) the investigation of self-perceived competencies in each construct. This study provides descriptive data about the moral imagination levels in undergraduate leadership students which will provide foundational information for the creation of curricula aimed at developing moral imagination, critical thinking, and moral decision making in this population.

\section{Methods}

Survey methods were used to achieve the purpose of this study (Fraenkel $\&$ Wallen, 2006). The moral imagination scale (MI) was the instrument used to collect data on students' level of moral imagination (Yurtsever, 2006). The MI scale consists of 29 items; 12 are positively worded and 17 are negatively worded items. There are three constructs for the MI scale: productive imagination, reproductive imagination, and creative imagination. Productive imagination includes sets of statements which describes the ability to increase awareness of contextual factors. Statements about reproductive imagination are focused on the ability to reframe a problem from other perspectives. Creative imagination includes statements which focus on an individual's "ability to envision and actualize novel, morally justifiable solutions to the problem” (Yurtsever, 2006, p. 208).

The researchers were granted permission to use the MI scale; however because the instrument was developed in Turkey, the translation created some ambiguity in the wording of 
the assessment. It was necessary to establish content-related evidence of validity, specifically in regard to appropriateness of language (Fraenkel et al., 2006). Therefore, three college students in the leadership program at one of the universities from which the sample was taken reviewed the instrument to ensure the use of language was appropriate for college students in the United States (Fraenkel et al. 2006). These students were not potential respondents for the study. Reliability was established in the development of the MI scale (Yurtsever, 2006). Reliability was calculated using Cronbach's alpha; coefficients were reported as: $r=.87$ for the total scale and a range from $r=.71$ to $r=.86$ for all subscales (Yurtsever, 2006). Construct validity was assessed for each of the 29 items and the scale was represented accurately for each. The MI utilized a seven-point summated scale with the following anchors: 1=Strongly Disagree, $2=$ Disagree, $3=$ Somewhat Disagree, 4=Neither Agree or Disagree, 5=Somewhat Agree, 6=Agree, and 7=Strongly Agree.

Prior to the instrument being administered, students were provided a definition of moral imagination and morals. The following definitions were used: moral imagination- the ability to imaginatively evaluate various possibilities for acting within a situation and to envision the good and bad likely to result from a given action; sympathetically taking the point of view of all those affected by a decision; morals-are founded on the principles of right conduct rather than legalities.

The population frame for this study was undergraduate students enrolled in leadership survey courses at two land grant universities with leadership degree programs; the potential population frame consisted of 290 students. Students were made aware that their participation was voluntary. Due to a combination of student absences and choice to not participate, there were a total of 151 instruments completed.

The data were analyzed using descriptive statistics, including means, percentages, standard deviations, minimums, and maximums (Field, 2009) to examine the self-perceptions of undergraduate leadership students' level of moral imagination. The data were analyzed by constructs. One respondent did not complete the demographics on the instrument. The population was a limitation of this study in terms of generalizability, as the respondents were students enrolled in two leadership survey courses at two large land grant universities with leadership degree programs. Students enrolled in these courses do not represent only those seeking a degree in leadership; they may be enrolled as part of a minor program, certificate program, and/or a general elective. However, the results do offer leadership educators insight on the moral imagination levels of undergraduate students, possible generalization to large land grant leadership student populations, and implied transferability to like contexts.

\section{Results}

One hundred fifty-one ( $\mathrm{n}=151)$ students responded to the survey; 69 respondents were from one university and 82 respondents were from the other university. The first objective of this study was to examine the self-perceptions of undergraduate leadership students' level of moral imagination. The highest perceived level of moral imagination is productive imagination $(M=5.21)$. The mean of 5.21 indicates that most students somewhat agree that they have abilities in productive imagination. Reproductive imagination also has a mean $(M=5.07)$ that indicates students somewhat agree they have competencies in this area. Creative imagination was found to 
be the level of moral imagination where students neither agreed nor disagreed that they had abilities $(M=4.84)$. Table 1 illustrates the means for each of the MI constructs.

Table 1.

- Descriptive Statistics of the Moral Imagination Constructs

\begin{tabular}{lccccc}
\multicolumn{1}{c}{ Construct } & $n$ & $M$ & SD & Min. & Max. \\
\hline $\begin{array}{l}\text { Productive Imagination } \\
\text { Reproductive }\end{array}$ & 151 & 5.21 & .73 & 3.57 & 7.00 \\
Imagination & 151 & 5.07 & .55 & 3.67 & 6.42 \\
Creative Imagination & 151 & 4.84 & .62 & 2.80 & 6.60 \\
\hline
\end{tabular}

Note. Scale: 1=Strongly Disagree, 2=Disagree, 3=Somewhat Disagree, 4=Neither Agree nor Disagree, 5=Somewhat Agree, 6=Agree, and 7=Strongly Agree.

Table 2 illustrates the descriptive statistics for the items in the reproductive imagination construct of the MI instrument. The highest mean occurred for the item "I have the ability to recognize which ideas are morally worth pursuing and which are not" $(M=5.87)$. This mean indicates that students somewhat agree they have abilities to complete this task. Students disagree $(M=2.74)$ that they have the competencies to discipline their abilities and tendencies to achieve self-control. As a whole, students either somewhat agreed or neither agreed nor disagreed that they had abilities in the reproductive imagination level of moral imagination. 
Table 2.

Descriptive Statistics for the Reproductive Imagination Construct in the Moral Imagination Scale

Item

morally worth pursuing and which are not.

I would identify various factors that could affect

the moral decisions of the organization.

My imagination would enable me to look at myself from another person's point of view.

I like to imagine the consequences of my behavior on others.

I could anticipate moral problems that threaten my organization.

I can create alternative solutions to new situations that need moral consideration.

I could imagine how my organizational decisions are informed in order to negotiate morally complex situations.

My moral imagination would help me anticipate unstated social factors on information that I receive related to moral decisions.

If I found myself uncertain about how to act in a morally unclear situation, I would rethink my basic understanding of a moral concept.

I could revise my existing moral beliefs to adapt to changing conditions.

In general, when there is a discussion about moral issues everyone tends to listen to me.

I can discipline all my abilities and tendencies to achieve self-control.
$M$

5.63

5.62

5.44

5.43

2.74
$S D$

1.01

.86

1.04

1.40

1.07

1.01

2

7

.98

3

7

1.07

1

7

1.61

1

7

Note. $n=151$. The grand mean and standard deviation for the construct Reproductive Imagination are $M=5.07, S D=.55$; Scale: 1=Strongly Disagree, 2=Disagree, 3=Somewhat Disagree, 4=Neither Agree or Disagree, 5=Somewhat Agree, 6=Agree, and 7=Strongly Agree. 
Table 3 illustrates the descriptive statistics for the productive imagination construct of the MI instrument. Individuals in this stage of moral imagination have the ability to imagine moral actions in a context. Overall, students in a leadership survey course at [universities] neither agreed nor disagreed or somewhat agreed with statements in this construct. The highest mean occurred for the item "I could put myself in the place of others" $(M=5.83)$. The lowest mean was associated with the item "It would be impossible to pursue my interests without other people interfering" $(M=4.20)$.

Table 3.

- Descriptive Statistics for the Productive Imagination Construct in the Moral Imagination Scale

Item

I could put myself in the place of others.

I have the ability to compare and contrast my own culture with other cultures.

My moral imagination increases my ability to understand morally relevant situations.

I have trouble understanding others' culture and values.*

It would be a waste of time for me to ask the opinion of the disagreeing group when I make a decision.*

I could resist any regulations detrimental to the environment, even at the risk of losing my current position in the organization.

It would be impossible to pursue my interests without other people interfering.*

M SD Min. Max.

5.83

1.04

2

7

$\begin{array}{llll}5.58 & 1.15 & 2 & 7\end{array}$

5.56

1.05

2

7

1.40

2

7

4.38

1.36

1

7

7

Note. $n=151$. The grand mean and standard deviation for the construct Productive Imagination are $M=5.21, S D=.73$; Scale: 1=Strongly Disagree, 2=Disagree, 3=Somewhat Disagree, 4=Neither Agree or Disagree, 5=Somewhat Agree, 6=Agree, and 7=Strongly Agree. *indicates item was reverse coded.

Table 4 illustrates the descriptive statistics for the creative imagination construct of the MI instrument. In general, there was much more disagreement about possessing competencies in this construct. The highest means indicated that students somewhat agreed they would be able to connect sensory data and intelligent thought $(M=5.44)$ and that they would not take moral responsibility for what they imagine may affect others $(M=5.43)$. The lowest was associated with envisioning alternatives to handle moral issues out of personal commitment $(M=2.97)$. 
Table 4.

- Descriptive Statistics for the Creative Imagination Construct in the Moral Imagination Scale

Item

It would be difficult for me to connect sensory

data (what I see, feel, hear, taste, etc.) and

intelligent thought.*

I would NOT take moral responsibility for what I

imagine in terms of affecting others.*

The amount and diversity of my social knowledge would NOT be sufficient to make moral decisions.*

I would NOT be able to imagine similarities and differences between similar situations where a certain rule or law applied.*

I am NOT able to conceive of moral standards that should be in place within a system.*

I would be careful about criticizing past decisions of the organization that were made under entirely different circumstances.

I could accept new organizational rules without any justification.*

I do NOT like to imagine the consequences of moral issues that would call for unusual facts.*

Once I generated reasons supporting my belief, I would find it difficult to generate contradictory

reasons.*

The reason I would be willing to envision creative and possible alternatives to handle moral issues is not personal reward, but a profound sense of personal commitment.

Note. $n=151$. The grand mean and standard deviation for the construct Creative Imagination are $M=4.84, S D=.62$; Scale: 1=Strongly Disagree, $2=$ Disagree, $3=$ Somewhat Disagree, $4=$ Neither Agree or Disagree, 5=Somewhat Agree, 6=Agree, and 7=Strongly Agree. * indicates item was reverse coded.
$M$

4.78
Min

$\operatorname{Max}$.

7

7

7

7

7

7

7

7 


\section{Conclusions}

The purpose of this study was to examine undergraduate leadership students' selfperceived level of moral imagination. This study was descriptive in nature and ultimately sought to provide foundational data for creating leadership curricula aimed at developing moral imagination, critical thinking, and moral decision making in college students.

In the reproductive imagination stage, individuals generate awareness of the contextual factors affecting their moral perceptions. Although this is the first stage in developing moral imagination, it ranked as the second highest construct reported by students $(M=5.07)$. Overall, students "somewhat agreed" with the statements concerning reproductive imagination. This finding is in contrast to the findings of Vidaver-Cohen (1997), Werhane (1998), and Yurtsever (2006). It can be concluded that individuals may not necessarily need an awareness of social, economic, organization, and personal factors that affect the perception of a problem and how moral conflicts might arise before being able to morally imagine at the productive stage.

Productive imagination involves a reframing of the problem from various perspectives. In this study, the undergraduate students surveyed reported their level of productive imagination the highest $(M=5.21)$. Werhane (1998) describes the moral imagination development process as a sequential process, therefore, it can be concluded that, although students perceived greater ability at this stage of moral imagination, they would perform even better with further development at the reproductive imagination stage. Further, it can be concluded that, while students "somewhat agreed" with statements concerning productive imagination, there is additional need for the development of skills before they can move into the creative imagination stage (Werhane, 1998). Imagination in the productive stage involves a willingness to challenge perspectives and understand characters, situations, and experiences that may indirectly or unintentionally affect a context (Werhane, 1998). Further, individuals would be able to categorize experiences and rethink the experience in different terms (Werhane, 1998, 1999). It is also noteworthy to consider the life-phase of the students who took this survey. The lowest scoring item addressed discipline for self-control. Whitely (2002) suggests that it is the obligation of colleges and universities to influence moral thinking and development; many times students see their tenure in higher education as an opportunity to forego some, if not many, of these qualities. In accordance with Jenkins (2012) and Williams (2013), it can be concluded that although these types of critical thinking concepts may be difficult to teach in a leadership classroom there are pedagogical techniques to develop these skills in the students pursuing higher education.

The final stage of moral imagination is creative imagination. Students reported this level of moral imagination capacities to be the lowest $(M=4.84)$. According to Werhane (1998), the creative imagination stage is the final stage of moral imagination and involves developing alternatives to problems which are novel and morally acceptable. It can be concluded that the students who participated in this study have not developed all necessary skills to be successful in this abstract stage of moral imagination. Enlow and Popa (2008) postulate that poor leadership may be the result of limited imagining; therefore, it can be concluded that the participating students must develop more advance, abstract imagining skills to be successful leaders in the future. Creative imagination may be the catalyst for creating new rules for organizations (Yurtsever, 2006) and develop novel and innovative concepts (Enlow \& Popa, 2008). 


\section{Recommendations}

The results of this study indicate that the participating students believe they have a moderate level of moral imagination skills; they did not strongly agree or strongly disagree in how they viewed their capacities to practice moral imagination. This identifies an opportunity for educators to take an active role in the development of students' moral imagination competencies.

Based on our exploration of leadership curricula, we found that students are introduced to the study of moral development and other theories of ethics and moral development in most leadership courses, but few address the specifics of moral imagination. The conclusion that students do not feel exceptionally skilled in moral imagination warrants a recommendation for the creation of curricula specifically addressing the development of student skills in moral imagination. Because moral imagination can be of great value in moving leaders from what is culturally or situationally prescribed to reassess past decisions and envision new possibilities (Werhane, 1999), leadership educators should consider teaching moral imagination in their curriculum. Swaner (2004) asserted that evidence exists to indicate moral reasoning continues to develop in college. As leadership educators, we are in a position to purposefully develop activities aimed at developing the moral reasoning and imagination of students.

Researchers, such as Enlow and Popa (2008), Liddell and Cooper (2012), Swaner (2004), and Whitely (2002) value educational intervention for the development of moral imagination. Based on the nature of the conceptual framework (Werhane, 1998; Yurtsever, 2006), we recommend that moral imagination curricula be developed with the goal of moving students through the three stages in a sequential process. This type of progression ensures students develop foundational competencies, such as critical thinking in moral decision making, in the reproductive imagination stage so they will be higher functioning at the subsequent stages.

One way to introduce moral imagination in the classroom is through the use of film. Enlow and Popa (2008) introduced the use of film as a means of teaching moral imagination. They proposed the use of film with the following learning objectives to contribute to the development of moral imagination: "(a) integrate fictional scenarios presented in the film to frame ethical systems and (b) understand the imaginative process as a method of connecting ethical situations with appropriate ethical responses" (Enlow \& Popa, 2008, p. 27). With advances in filming technologies (i.e., cell phones, tablet computers, etc.), we recommend that instructors combine showing film in the class and assigning the students to create film to link course content to situation in the students' lives. Reusable learning objects are a direct way to encourage experiential learning though the combination of peer education and content application by linking course content to situations in their lives. The nature of a reusable learning object guides the creator to gather media rich content in the context of a desired learning objective and assessment (Murphrey, Sandlin, Lindner, \& Dooley, 2013).

Enlow and Popa (2008) discussed difficulties in teaching the skill of imagination; it requires unique pedagogical approaches in helping individuals identify existing mental models along with engaging them in new ways of knowing and seeing. We recommend the instrument be used as a teaching tool and self-assessment to provide student feedback on their progression through the productive, reproductive, and creative imagination stages. The MI instrument 
provides a unique opportunity to measure students' moral imagination capacities and educate on the skills needed to be successful in each stage. The instrument items are stage-specific imagination skills. The formatting of the instrument could be arranged to group items by imagination stage allowing students to better conceptualize the types of capacities that each stage entails. Curricula could be structured to discuss each level of moral imagination and how to build skills in each level; pre/post testing using the MI instrument would show students their progression through the stages. While it may be difficult to teach, moral imagination development can prevent ethical mistakes from occurring in organizations (Werhane, 1999).

Further, we support the use of creative means in developing moral imagination curricula. We recommend educators create contexts that support the imaginative process and predispose students to using moral imagination. Specifically, case studies rooted in tangible real-life and even campus-based examples can be powerful for educators as they attempt to develop moral imagination in their leadership students. Students relate to immediately pressing issues such as student fee allocation, international fair trade, and community-based development effort examples. These examples ask students to consider their past experiences (reproductive imagination), understand emergent stimuli impacting their decision (productive imagination), and develop morally-grounded decision-making perspectives substantiated in systems thinking and utilitarian reasoning (creative imagination). These examples require that educators stay informed of current issues and events and also increase their own levels of moral imagination as they must assess student performance.

Further research should investigate how students demonstrate their level of moral imagination skill. Because this instrument used self-reported data, students may have overrated themselves in terms of their ability. We believe that it is critical to continue this line of inquiry in an effort to properly assess students' levels of proficiency and identify foundational data that can help to shape leadership ethics and morality curricula. Finally, we believe that research should be dedicated to understanding the influence of specific pedagogies on the moral imagination levels of leadership students. The potential benefits associated with the inclusion of moral imagination based leadership curriculum cannot be overstated. It is operationally, strategically, and purposively necessary for the future of morally-grounded and ethically-sound organizations along with its indelible link to successful interpersonal leadership. It has the potential to be a catalyst for enhanced organizational practice and community sustainability.

\section{References}

Enlow, B. \& Popa, A. B. (2008). Fostering moral imagination in leadership students. Journal of Leadership Education, 7(2), 24-31.

Field, A. (2009). Discovering statistics using SPSS (3rd ed.). New York, NY: The McGraw-Hill Companies.

Fraenkel, J. R., \& Wallen, N. E. (2006). How to design and evaluate research in education (6th ed.). New York, NY: The McGraw-Hill Companies. 
Greenfield, W. (2004). Moral leadership in schools. Journal of Educational Administration, 42(2), 174-196.

Jenkins, D. M. (2012) Exploring signature pedagogies in undergraduate leadership education. Journal of Leadership Education, 11(1), 1-27.

Liddell, D. L., \& Cooper, D. L. (2012). Moral development in higher education. New directions for student services, 2012(139), 5-15. doi: 10.1002/ss.20018.

Macintyre, A. (2013). After virtue: A study in moral theory. London, England: Bloomsbury Academic. doi: CBID169758.

Maddi, S. R. (1999). The personality construct of hardiness: I. Effects on experiencing, coping, and strain. Consulting Psychology Journal: Practice and Research, 51(2), 83-94.

Murphrey, T. P., Sandlin, M. R., Lindner, J. R., \& Dooley, K. E. (2013). Reusable learning objects: Faculty perceptions and best practices in a college of agriculture. NACTA Journal, 57(1), 47-54.

Narvaez, D., \& Lapsley, D. K. (2007). Moral identity, moral functioning, and the development of moral character. Psychology of Learning and Motivation, 50, 237-274.

Narvaez, D., Lapsley, D. K., Hagele, S., \& Lasky, B. (2006). Moral chronicity and social information processing: Tests of a social cognitive approach to the moral personality. Journal of Research in Personality, 40, 966-985.

Oddo, A. R. (1997). A framework for teaching business ethics. Journal of Business Ethics, 16(3), 293-297.

Pijanowski, J. (2007). Defining moral leadership in graduate schools of education. Journal of Leadership Education, 6(1), 1-13.

Sims, R. R., \& Sims, S. J. (1991). Increasing applied business ethics courses in business school curricula. Journal of Business Ethics, 10(3), 211-219.

Smith, A. (2002). The theory of moral sentiments. In K. Haakonssen (Ed.) Retrieved from [Ebsco Host]. (Original work published in 1976). New York: Cambridge University Press.

Smith, M. W., \& Carter, H. (2012). Ethics and morals in leadership, a review of the literature. Paper presented at the 2012 Annual Conference of the Association Leadership Educators, Key West, FL. Abstract Retrieved from http://leadershipeducators.org/Resources/Documents/2012\%20ALE\%20Conference\%20 Proceedings .pdf 
Swaner, L. E. (2004). Educating for personal and social responsibility: A planning project of the association of American colleges and universities. Retrieved from http://www.aacu.org/core_commitments/documents/review_of_lit.pdf

Vidaver-Cohen, D. (1997). Moral imagination in organizational problem-solving: An institutional perspective. Business Ethics Quarterly, 3, 1-26.

Wenger, E. (1998). Communities of practice. Cambridge: Cambridge University Press.

Werhane, P. H. (1998). Moral imagination and the search for ethical decision making in management. The Ruffin Series of the Society for Business Ethics, 1, 75-98. doi: 10.5840/ruffinx 199815.

Werhane, P. H. (1999). Moral imagination and management decision-making. Oxford: Oxford University Press.

Werhane P. H. (2002). Moral imagination and systems thinking. Journal of Business Ethics, $38(1 / 2), 33-42$.

Werhane, P. H. (2006). A place for philosophers in applied ethics and the role of moral reasoning in moral imagination: A response to Richard Rorty. Business Ethics Quarterly, 16 (3), 401-408.

Werhane P. H., \& Moriarty B. (2009). Moral imagination and management decision-making. Retrieved from

http://www.corporate-ethics.org/pdf/moral_imagination.pdf

White, B. J. (2006). Design and implementation of an interdisciplinary leadership studies minor at an historically black, liberal arts college. Journal of Leadership Education, 5(2), 50-59.

Whiteley, J. M. (2002). Exploring moral action in the context of the dilemmas of young adulthood. Analytic Teaching, 20(1), 4-25.

Williams, J. (2013). Analyzing cultural artifacts for the introduction, perpetuation, or reinforcement of moral ideals. Journal of Leadership Education, 12(1), 245-251.

Yurtsever, G. (2003). Measuring the moral entrepreneurial personality. Social behavior and personality, 31, 1-12.

Yurtsever, G. (2006). Measuring moral imagination. Social Behavior and Personality, 34(3), 205-220. 


\section{Author Biographies}

Summer F. Odom, Ph.D. is an Assistant Professor in the Department of Agricultural Leadership, Education, \& Communications (ALEC) at Texas A\&M University. She teaches courses in personal and professional leadership. Dr. Odom received her Ph.D. in Human Resource Development in May 2011. Some of her research interests include programmatic assessment and evaluation of leadership programs and the psychological development of leaders, followers, and learners.

Tony Andenoro, Ph.D., is currently serving as an Assistant Professor of Leadership Education within the Department of Agricultural Education, the Challenge 2050 Project Academic Director, and the Coordinator of the campus-wide Leadership Minor at the University of Florida. He earned his PhD in Agricultural Education with an emphasis in Leadership from Texas A\&M University and his research interests include development of emotionally engaged thinking through dynamic educational means and examining socially vulnerable contexts in an effort to develop hardiness, resilience, and community sustainability.

M'Randa Sandlin is an Assistant Researcher at the University of Hawai ' $i$ at Mānoa in the College of Tropical Agriculture and Human Resources. Dr. Sandlin received her Ph.D. in Agricultural Leadership, Education, and Communications from Texas A\&M University where she also taught courses in personal and professional leadership. Her research interests include public opinions of critical agricultural and natural resource issues and leadership development for critical issue mitigation.

Jaron Jones, Ph.D. Candidate is a third year student studying Leadership Education at the University of Florida. He received his Bachelors degree in Soil Science and his Masters degree in Agriscience Education from North Carolina A\&T State University. His research interests include finding creative methods to teach leadership as well as using self-narration to enhance self-image, self-efficacy and personal hardiness in individuals. He advocates for everyone to find strength and beauty within their own story. 